\title{
FORMULATION AND EVALUATION OF CEFIXIME TRIHYDRATE TOPICAL GEL FOR WOUND INFECTIONS
}

\author{
UMA SHANKAR MARAKANAM SRINIVASAN*, VISHNU, SHARMILA, AMOD KUMAR \\ Department of Pharmaceutics, SRM College of Pharmacy, SRM Institute of Science and Technology, Kattankulathur - 603 202, \\ Kanchipuram, Tamil Nadu, India. Email: umashankarms.umashankar1@gmail.com
}

Received: 22 March 2018, Revised and Accepted: 08 May 2018

\section{ABSTRACT}

Objective: The objective of this research work was to formulate and evaluate topical gel loaded with cefixime trihydrate, a third-generation cephalosporin antibiotic for the treatment of bacterial wound infections.

Methods: The cefixime trihydrate gel was formulated using polymers such as Carbopol 940 and hydroxypropyl methylcellulose E4M in varying concentrations. Three different formulations were prepared and characterized physically for color, syneresis, spreadability, pH, drug content, and rheological properties. In vitro drug release in phosphate buffer $\mathrm{pH} 7.4$ and antibacterial study were performed for the gel formulation to evaluate its therapeutic effect on wound infections.

Results: The study demonstrated that the gel formulations showed promising results on their physical evaluation tests. The rheology behavior of the gel was shear-thinning flow type which indicated easy spreading of the gel. The drug release of the gel formulation F2 was selected as the best due to its highest drug release rate of $32.2 \%$ in comparison with the other two formulations after $2 \mathrm{~h}$ of the study. F2 formulation possessed the highest antibacterial activity as compared to other two formulations.

Conclusion: A pioneering work was done on formulating cefixime trihydrate as a gel for topical administration. The antibacterial effect of the drug as gel formulation showed promising effect. We conclude that the cefixime trihydrate could be successively loaded into a gel formulation and can be used for effectively for wound infections like diabetic foot wounds.

Keywords: Cefixime trihydrate, Antibiotic gel, Wound infection, Diabetic foot wounds.

(C) 2018 The Authors. Published by Innovare Academic Sciences Pvt Ltd. This is an open access article under the CC BY license (http://creativecommons. org/licenses/by/4. 0/) DOI: http://dx.doi.org/10.22159/ajpcr.2018.v11i8.26150

\section{INTRODUCTION}

Human body skin is the largest organ that has 2 sq.m lengths and thickness of $2.970 .28 \mathrm{~mm}$. It controls body temperature and protects the skin from hazardous rays and pollutants. Skin serves as a permeability barrier for bioactive agents [1]. The skin composed of epidermis and dermis, viable epidermis contains stratum lucidum, stratum granulosum, stratum spinosum, and stratum basale. Dermis is the layer of skin beneath the epidermis contains blood vessels, lymph vessels, and nerves. The two main routes of skin permeation are transepidermal route and transfollicular route [2,3]. Wound healing is a complex process that occurs in tissues after damage. Hemostasis involves vascular constriction, platelet aggregation, and fibrin clot formation, and development of a scab that provides protection, and strengthens the damaged tissue. During repair, platelets release several growth factors, transforming growth factor- $\beta$, epidermal growth factor, platelet-derived growth factor. The healing process involves the migration and infiltration of inflammatory cells into the wound and supports for capillary growth, collagen synthesis, and new tissue formation.

Chronic wounds such as venous ulcers and ischemic wounds can disrupt the normal regeneration process and results in bacterial colonization leads to delayed healing process. Chronic wounds make longer hospitalization times and cellular tissue-engineered skin substitutes and medicated dressings increasing medical costs. To prevent delayed healing and improve the healing process and better treatment options for chronic wounds are still very limited. To address this needs and effective efforts have been performed in the present our research into traditional therapies as alternative clinical treatments for the treatment of chronic wounds.
Transdermal permeation is a passive diffusion, the release of therapeutic agent from the formulation applied over the skin surface and its transport into the systemic circulation [4]. Gels are semi-solids dispersion system contains suspension of drug in a liquid phase [5,6]. Gels are translucent, non-greasy, and semi-solid gels. It consists of large proportion of water and added preservatives. Topical gel provides a localized drug delivery for ophthalmic, rectal, vaginal and skin diseases, and wounds $[7,8]$. Drugs applied to the skin for their local action include antiseptics, analgesics, antifungal agents, skin emollients, and as protectants [9]. Cefixime trihydrate is a third generation cephalosporin antibacterial drug. The antibacterial effect of cefixime trihydrate results from inhibition of mucopeptide synthesis in the bacterial cell wall. It is active against Gram-positive and Gram-negative microorganisms. Cefixime trihydrate is available as oral and parenteral dosage forms in the market [10].

\section{MATERIALS AND METHODS}

Materials

Cefixime trihydrate was procured from Orchid Chemical Pvt., Ltd. as gift sample. All the other chemicals were purchased from Sisco Research laboratories, Pvt., Ltd. Reagents used were within the laboratory specifications.

\section{Methods}

Preparation of standard curve for cefixime trihydrate

Standard stock solution was prepared by dissolving $10 \mathrm{mg}$ of cefixime trihydrate in $20 \mathrm{ml}$ of methanol in a $100 \mathrm{ml}$ volumetric flask and the volume was made up with phosphate buffer $\mathrm{pH} 7.4$ to get $100 \mu \mathrm{g} / \mathrm{ml}$ concentration. The flask was kept on a mechanical shaker to dissolve 
any undissolved particles. From the stock solution, a serial dilutions of 2 , $4,6,8$, and $10 \mu \mathrm{g} / \mathrm{ml}$ concentrations were made using phosphate buffer $\mathrm{pH} 7.4$ and absorbance were taken at $234 \mathrm{~nm}$ using ultraviolet (UV) visible spectrophotometer with phosphate $\mathrm{pH} 7.4$ as blank. Averages of 3 sets of values were taken and summarized in (Table 1and Fig. 1) and the standard curve was plotted [11].

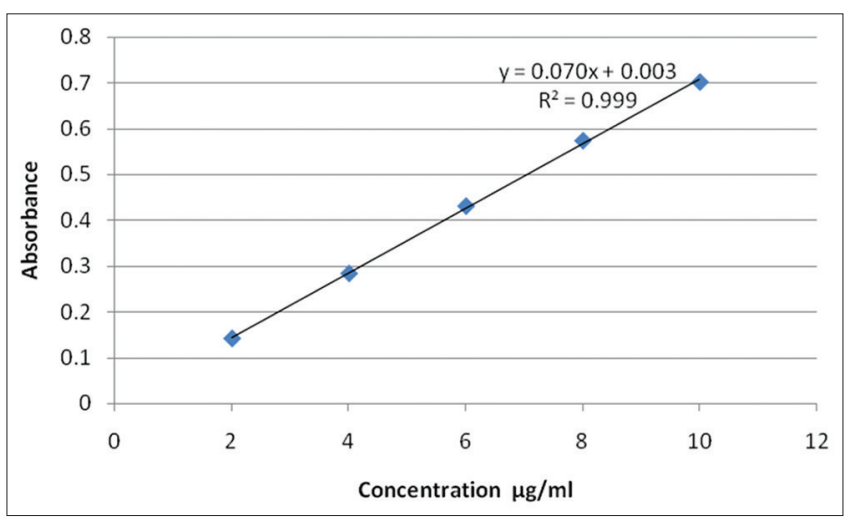

Fig. 1: Standard calibration curve of cefixime trihydrate

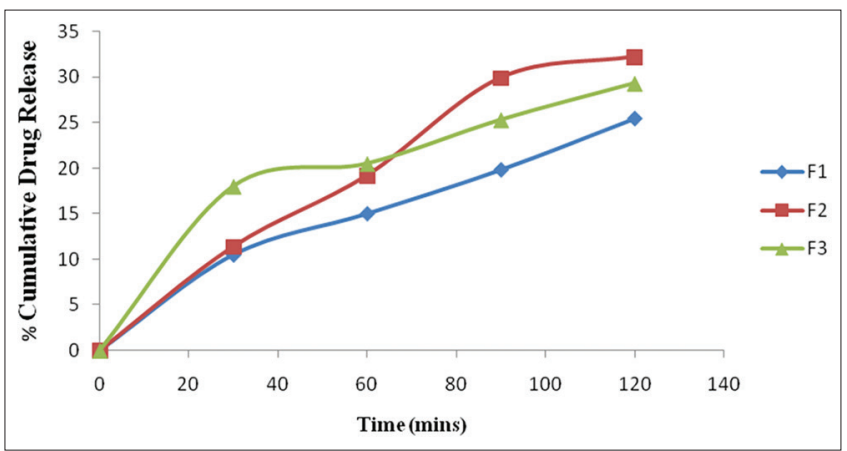

Fig. 2: In vitro drug release profile of cefixime trihydrate gels

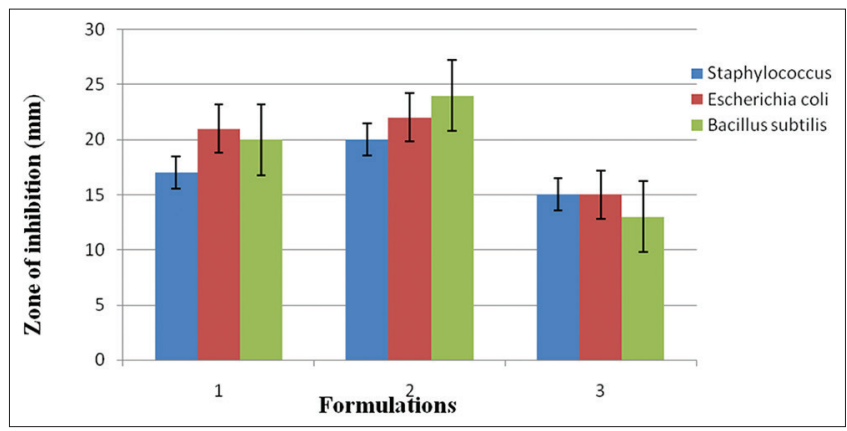

Fig. 3: Antibacterial activity of the cefixime trihydrate gels

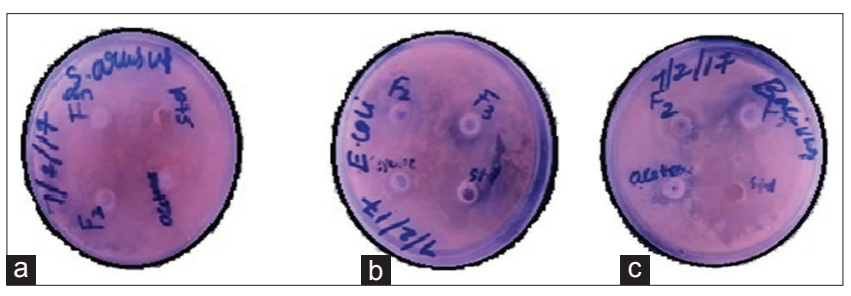

Fig. 4: (a-c) Antibacterial activity of the cefixime trihydrate topical gels
Formulation of cefixime trihydrate gel

Cefixime trihydrate $(3 \% \mathrm{w} / \mathrm{w})$ was dissolved in a mixture of propylene glycol $(5 \% \mathrm{w} / \mathrm{v})$ and glycerin $(5 \% \mathrm{w} / \mathrm{v})$ as moistening agent. Oleic acid and ethanol were added into it. Carbopol 940 and hydroxypropyl methyl cellulose polymer mixture were added into warm water with constant stirring on a magnetic stirrer at a moderate speed to get a uniform polymer mixture, Table 2 .

The drug mixture was then added to the polymer mixture and continued stirring for $1 \mathrm{~h}$. Tween 80 was added as suspending agent followed by methylparaben and propylparaben as preservatives. The $\mathrm{pH}$ of the mixture was adjusted using triethanolamine. Gel was formation by the transition from sol to gel at $4^{\circ} \mathrm{C}$. Cefixime trihydrate gel was packed in a wide-mouthed glass jar and stored in a cool place [12].

\section{Characterization of cefixime trihydrate gels}

\section{Visual examination}

Gels were inspected for homogeneity, color; syneresis and lumps by visual inspection [13].

\section{Spreadability test}

A $0.5 \mathrm{~g}$ of gel was pressed between two slides, divided into squares of $5 \mathrm{~mm}$ sides and left for about $5 \mathrm{~min}$. The spreading was measured, and

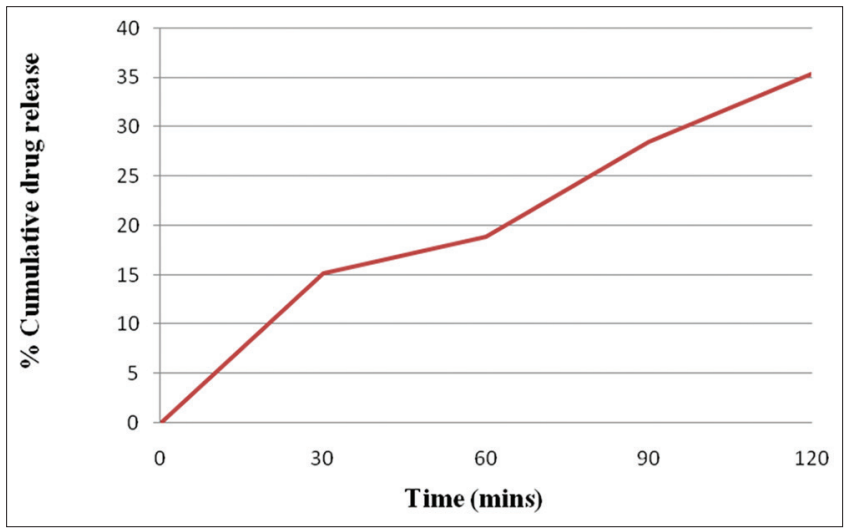

Fig. 5: In vitro drug release from formulation F2 after 3 months

Table 1: Standard curve of cefixime trihydrate

\begin{tabular}{lll}
\hline S.No & Concentration $(\boldsymbol{\mu g} / \mathbf{m l})$ & Absorbance $(\mathbf{n m})$ \\
\hline 1 & 2 & 0.142 \\
2 & 4 & 0.284 \\
3 & 6 & 0.431 \\
4 & 8 & 0.574 \\
5 & 10 & 0.702 \\
\hline
\end{tabular}

Table 2: Composition of cefixime trihydrate gel $(\% \mathrm{w} / \mathrm{w})$

\begin{tabular}{llll}
\hline Ingredients & F1 & F2 & F3 \\
\hline Cefixime trihydrate $(\mathrm{g})$ & 3 & 3 & 3 \\
Carbopol 940 $(\mathrm{g})$ & 1 & 1.5 & 2 \\
HPMC $(\mathrm{g})$ & 0.5 & 0.5 & 2 \\
Propylene glycol (g) & 5 & 5 & 5 \\
Triethanolamine (g) & 0.5 & 0.5 & 0.5 \\
Oleic acid (g) & 1 & 1 & 1 \\
Ethanol (ml) & 1.5 & 1.5 & 1.5 \\
Tween 80 (g) & 0.5 & 0.5 & 0.5 \\
Glycerin (g) & 5 & 5 & 5 \\
Methylparaben (g) & 0.03 & 0.0 .3 & 0.03 \\
Propylparaben (g) & 0.01 & 0.01 & 0.01 \\
Water (ml) & 80.5 & 80.5 & 80.5 \\
Total (g) & 100 & 100 & 100 \\
\hline
\end{tabular}


Table 3: Physical properties of cefixime trihydrate gels

\begin{tabular}{llllll}
\hline Gel & Color and appearance & Syneresis & *Spreadability $\mathbf{( c m )}$ & pH & *Drug content (mg/gm) \\
\hline F1 & Buff and Opaque & -ve & $8 \pm 0.57$ & 5.4 & $9.3 \pm 0.05$ \\
F2 & Transparent & -ve & $5 \pm 0.57$ & 5.67 & $9.5 \pm 0.05$ \\
F3 & Yellow and transparent & -ve & $3.4 \pm 0.20$ & 7.24 & $9.4 \pm 0.10$ \\
\hline
\end{tabular}

*The spreadability and drug content of all the three formulations were found to be statistically significant

Table 4: Reological properties of cefixime trihydrate gels

\begin{tabular}{llll}
\hline Formula & *Flow index (n) & *Viscosity (Cp) (n) & \\
No. & & Flow behavior & \\
\hline F1 & $0.1390 \pm 0.0003$ & $1012 \pm 1.00$ & Shear thinning \\
F2 & $0.1214 \pm 0.0001$ & $1449 \pm 2.08$ & Shear thinning \\
F3 & $0.2307 \pm 0.0002$ & $2441 \pm 3.05$ & Shear thinning \\
\hline
\end{tabular}

*The flow index and viscosity of all the three formulations were found to be statistically significant

Table 5: In vitro release data of cefixime trihydrate gels

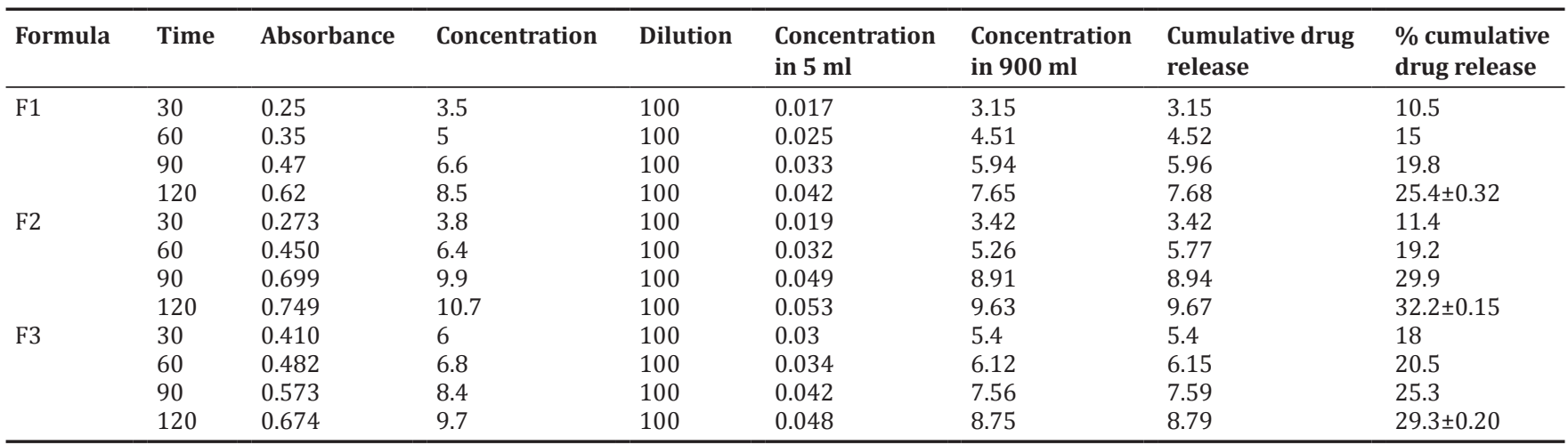

*The in vitro drug release of three formulations was found to be statistically significant

Table 6: Antibacterial study of cefixime trihydrate gel

\begin{tabular}{llll}
\hline Formulations & Inhibition zone $(\mathbf{m m})$ & \\
\cline { 2 - 4 } & Staphylococcus aureus & $\begin{array}{l}\text { Escherichia } \\
\text { coli }\end{array}$ & B. subtilis \\
\hline F1 & $17 \pm 0.2$ & $21 \pm 0.2$ & $20 \pm 0.2$ \\
F2 & $20 \pm 0.1$ & $22 \pm 0.2$ & $24 \pm 0.1$ \\
F3 & $15 \pm 0.2$ & $15 \pm 0.1$ & $13 \pm 0.1$ \\
\hline
\end{tabular}

S. aureus: Staphylococcus aureus, E. coli: Escherichia coli, B. subtilis: Bacillus subtilis *The antibacterial study of three formulations was found to be statistically significant. The antibacterial effect of F1, F2, and F3 was in agreement with the drug release from the gel formulations which ensue by the effect of the polymers added.

the results were shown in Table 3. Averages of 3 sets of values were taken.

\section{pH determination}

The $\mathrm{pH}$ of the gel was determined using digital $\mathrm{pH}$ meter. The readings were taken on an average of 3 . The results were shown in Table 3.

\section{Drug content determination}

A specified quantity of gel was dissolved in a $100 \mathrm{ml}$ of phosphate buffer $\mathrm{pH} 7.4$ taken in a volumetric flask. It was shaken for $2 \mathrm{~h}$ on a mechanical shaker to get complete solubility of the drug. The solution was then filtered using Millipore filter $(0.45 \mu \mathrm{m})$. After suitable dilution of the filtrate, the absorbance was recorded using UV-visible spectrophotometer at the $\lambda_{\max }$ at about $234 \mathrm{~nm}$ using phosphate buffer pH 7.4 as blank. The results were shown in Table 3. Averages of 3 sets of values were taken.

\section{Rheological study}

The viscosity of the gel was determined using Brookfield viscometer with spindle CPE- 41 at $25^{\circ} \mathrm{C}$. The viscosity was determined at the shear rate of $40 \mathrm{~s}-1$ using the equation $\tau=\mathrm{k} \gamma \mathrm{n}$, where " $\tau$ " is the shear stress, " $\gamma$ " is the shear rate, $\mathrm{k}$ is the consistency index, and $\mathrm{n}$ is the flow index, if $\mathrm{n}>1$ or $\mathrm{n}<1$, shear thickening or shear thinning is indicated, respectively [13]. The results were shown in Table 4. Averages of 3 sets of values were taken.

\section{In vitro release study}

One gram of cefixime trihydrate gel was placed in a glass dish covered with an aluminum sieve. The glass dish was then immersed in the bowl containing $500 \mathrm{ml}$ of the release medium, phosphate buffer $\mathrm{pH} 7.4$ at $37^{\circ} \mathrm{C} \pm 0.5^{\circ} \mathrm{C}$ fitted with a paddle at a speed of $50 \mathrm{rpm}$ [14]. Aliquots of 5 $\mathrm{ml}$ were withdrawn at specified time intervals and replaced with fresh dissolution medium to maintain the sink. The samples were assayed spectrophotometrically at $\lambda_{\max } 234 \mathrm{~nm}$, and the concentration of the drug was determined. Experiments were carried out in triplicates. The results were shown in Table 5 and Fig. 2. Averages of 3 sets of values were taken.

\section{Antibacterial activity study}

The antibacterial activity was performed on agar cup-plate method using Staphylococcus aureus, Escherichia coli, and Bacillus subtilis by measuring the inhibition zone. The results were shown in Table 6 , Figs. 3 and 4. Averages of 3 sets of values were taken.

\section{Stability study}

The stability study was carried out for the most satisfactory formulation as per the ICH guidelines. The selected formulation was stored at room temperature for a 6 months period. At the end of each month, the sample was analyzed for their physical properties, spreadability, $\mathrm{pH}$, the drug content, rheological property, drug release, and antibacterial activity [15]. 
Table 7: Stability studies of the optimized cefixime trihydrate topical gel formulation F2

\begin{tabular}{lllllll}
\hline Topical gel & Color and appearance & Syneresis & Spreadability $\mathbf{( c m )}$ & pH & Drug content (mg/gm) & Flow behavior \\
\hline F2 & Transparent & -ve & 9.2 & 7.5 & 9.23 & Shear thinning \\
\hline
\end{tabular}

Table 8: In vitro release study of optimized cefixime trihydrate topical gel formulation F2

\begin{tabular}{lll}
\hline Formulation & Time & \% Cumulative drug release \\
\hline F2 & 30 & 15.2 \\
& 60 & 18.9 \\
& 90 & 28.5 \\
& 120 & 35.4 \\
\hline
\end{tabular}

\section{RESULTS AND DISCUSSION}

\section{Standard calibration curve of cefixime trihydrate}

Standard calibration curve showed linearity and obeyed Beer'sLambert's law. The curve was used for studying the in vitro drug release.

\section{Characterization of cefixime trihydrate gels}

The developed gels were inspected visually for their color and syneresis. F1 gel was buff colored and opaque. F2 and F3 gel formulations showed good homogeneity, transparency, with no lumps, and syneresis. The results were shown in Table 3.

\section{Spreadability test}

The diameter of the spread circles was $8 \mathrm{~cm}$ with F1, $5 \mathrm{~cm}$ with F2, and $3.4 \mathrm{~cm}$ with F3, which revealed that increase in the concentration of the gelling agent causes, decreased spreading as expressed by the lower diameter of the spread circle. The results were shown in Table 3.

\section{Drug content}

The drug content of the gel was estimated, and the results were within the official limits range of $9.3-9.5 \mathrm{mg} / \mathrm{g}$ gel. The drug content determination showed that the drug was uniformly distributed throughout the gel. Results were shown in Table 3.

\section{pH determination}

The $\mathrm{pH}$ of the developed gels was in the range 5-7 for F1-F3, which was considered acceptable and the gels were devoid of any irritation onto the skin. Results were shown in Table 3.

\section{Rheological study}

The gel showed $n<1$ possessing shear thinning effect with optimum viscosity enabling spreading over the skin surface. Shear thinning favor easy application, good spreadability, and uniform drug absorption over the wounds affected area. Results were shown in Table 4.

\section{In vitro release study}

The in vitro release profile of the formulations F1, F2, and F3 gels were carried out. It was observed that the release of the drug from formulation F2 was higher than F1 and F3. The amount of the drug released after $2 \mathrm{~h}$ from formulation $\mathrm{F} 2$ was $32.2 \%$, whereas $25.3 \%$ from $\mathrm{F} 1$ and $29.3 \%$ from $\mathrm{F} 3$, respectively. It could be the reason that the implication of the drug-polymer entanglement causing indifferential drug release by dissolution induced diffusion mechanism due to an effective therapeutic bioavailability of the drug. The results were combined in Table 5 and showed in Fig. 2.

\section{Antibacterial activity of cefixime trihydrate gel}

The study revealed F2 gel having the greatest antibacterial activity as compared to F1 and F3 with the inhibition zone for S. aureus $20 \mathrm{~mm}$, E. coli $22 \mathrm{~mm}$, and B. subtilis $24 \mathrm{~mm}$, respectively. F1 gel showed S. aureus $17 \mathrm{~mm}$, E. coli $21 \mathrm{~mm}$, and B. subtilis $20 \mathrm{~mm}$, respectively. F3 gel formulation showed S. aureus $15 \mathrm{~mm}$, E. coli $15 \mathrm{~mm}$, and B. subtilis $13 \mathrm{~mm}$, respectively. The F2 showed more prominent antibacterial activity against B. subtilis as compared to the other species studied. The antibacterial activity of the gel formulations F1, F2, and F3 was shown in Table 6 and Fig. 3.

\section{Stability study}

The optimized cefixime trihydrate gel formulation F2 was subjected to stability study according to ICH guidelines. The result showed that the formulation was remained stable on storage for 3 months at room temperature with no any significant changes observed in the parameters evaluated such as color and appearance, syneresis, spreadability, $\mathrm{pH}$, drug content, and rheological properties Table 7 [16]. The in vitro drug release of the optimized formulation F2 was conducted and the result was shown in Table 8 and Fig. 5.

\section{DISCUSSION}

The cefixime trihydrate could be successfully incorporated in the topical gel formulations by varying the polymer concentrations. Among the developed formulations, F2 showed good appearance, spreadability, viscosity, drug release, and antibacterial activity. The antimicrobial activity of the cefixime trihydrate contributed to the wound healing effect by eliminating infection which allows the natural tissue repair process to establish. Our study results meet the research study conducted by Khatri et al. [17] which indicated that the semisolid dosage formulations can improve the effective management of wounds. This novelistic approach of formulating an alternative topical administration of third-generation cephalosporin, Cefixime trihydrate will prove to be a boon to treat various infections including diabetic foot ulcer infections of the diabetic patients.

\section{CONCLUSION}

The present study had demonstrated that a topical gel formulation loaded with cefixime trihydrate can be made more promisingly, providing an efficient topical alternative for wound healing treatment which may include management of diabetic foot ulcer infections as a diabetic wound care gel.

\section{AUTHOR'S CONTRIBUTION}

M.S. Umashankar: Designed the study protocol. Vishnu done experimental study and carried out analysis, Sharmila and Amod Kumar: The manuscript was drafted.

\section{CONFLICTS OF INTEREST}

Declared none.

\section{ACKNOWLEDGMENT}

We would like to thank Dr. K.S. Lakshmi, Dean, SRM College of Pharmacy, SRM Institute of Science and Technology, Tamil Nadu, India, for her valuable support.

\section{REFERENCES}

1. Ramachandani U. Formulations and evaluation of topical gel of ketoprofen using different polymers. Inter J Pharm Bioarch 2013;2:323-6.

2. Thomas SK, George RE, Kunjumon M, Thankamani V. In vitro antibacterial profile of Alstonia venenata $\mathrm{R}$. BR-a comparative study. Int J Curr Pharm Res 2015;7:86-8.

3. Alaayed M, Mahmood H, Saeed A. The enhancement effect of castor oil on the permeability of flurbiprofen as Transdermal gel. Int J Appl Pharm 2018;10:140-4

4. Nanda S, Saroha KA, Sharma BE. Formulation, evaluation and 
optimization of transdermal gel of ketorolac tromethamine using face centered central composite design. Int J Pharm Pharm Sci 2014;4:133-9.

5. Usama FA. Preparation and evaluation of novel topical gel preparation for wound healing in diabetics. Int J Pharm Pharm Sci 2012;4:76-8.

6. Helal DA, El-Rhman DA, Abdel-Halim SA, El-Nabarawi MA. Formulation and evaluation of fluconazole topical gel. Int J Pharm Pharm Sci 2012;5:176-83

7. Toppo FA, Pawar RS. Novel drug delivery strategies and approaches for wound healing managements. J Crit Rev 2015;2:12-20.

8. Vats A, Sharma P. Formulation and evaluation of topical anti-acne formulation of coriander oil. Int J Pharm Pharm Sci Res 2012;2:61-6.

9. Agnihotri S, Wakode S, Agnihotri A. Formulation and evaluation of herbal anti-acne gel of Myrica esculenta. Asian J Pharm Clin Res 2016;4:358-61.

10. Harahap NI, Nainggolan M, Harahap U. Formulation and evaluation of herbal antibacterial gel containing ethanolic extract of Mikania micrantha kunth leaves. Asian J Pharm Clin Res 2018;3:429-31.

11. Vasanth S, Bupesh G, Vijayakumar TS, Balachandar V, Gunasekaran D.
Evaluation of in vitro anti diabetic and antioxidant potential of Barleria cristata leaves extracts. Asian J Pharm Clin Res 2018;4:287-90.

12. Reza MI, Goel D, Gupta RK, Warsi MH. Formulation of ketoconazole loaded nano dispersive gel using swollen micelles technique and it's in vitro characterization. Inter J Pharm Pharm Sci 2018;3:162-6.

13. Madhuri A, Theng GR, Biyani SK. Evaluation of wound healing activity of poly herbal formulation. Int J Curr Pharm Res 2017;9:12-4.

14. Sritharadol R, Nakpheng T, Heng PS, Srichana T. Development of a topical mupirocin spray for antibacterial and wound-healing Applications. Drug Dev Pharm 2017;43:1715-28.

15. Attama AA, Uzor PF, Nnadi CO, Okafor CG. Evaluation of the wound healing activity of gel formulations of leaf extract of Aspila africana Fam. Compositae. J Chem Pharm Res 2011;3:718-72.

16. Ponnekanti K, Rajan RS. Development and validation of New RPUPLC method for the determination of Cefdinir in bulk and dosage form. Int J Pharm Pharm Sci 2018;1:178-84.

17. Khatri SK, Rathnanand M, Nikhila R. Formulation and evaluation of wound healing activity of Linezolid topical preparations on diabetic rats. Int J Appl Pharm 2016;8:30-6. 